\title{
Article \\ Questioning Our Credibility: An Exploration of the Professional Identity Development of Mathematics Teacher Educators
}

\author{
Dionne Cross Francis ${ }^{1, *}$, Pavneet Kaur Bharaj ${ }^{1}{ }^{\circledR}$, Jinqing Liu ${ }^{2}$, Andrea Phillips ${ }^{3}$, Meredith Park Rogers ${ }^{3}$, \\ Qiu Zhong ${ }^{3}$, Claire Cesljarev ${ }^{3}$ and Kemol Lloyd $^{3}$ \\ 1 School of Education, University of North Carolina at Chapel Hill, 100 E Cameron Ave, \\ Chapel Hill, NC 27514, USA; pkbharaj@unc.edu \\ 2 College of Engineering \& Physical Sciences, University of New Hampshire, 33 Academic Way, \\ Durham, NH 03824, USA; jinqliu@iu.edu \\ 3 School of Education, Indiana University, 102 N Rose Ave, Bloomington, IN 47405, USA; \\ philland@iu.edu (A.P.); mparkrog@indiana.edu (M.P.R.); zhongqiu@iu.edu (Q.Z.); ccesljar@iu.edu (C.C.); \\ kemlloyd@indiana.edu (K.L.) \\ * Correspondence: dicross@unc.edu; Tel.: +1-404-734-1084
}

Citation: Cross Francis, D.; Kaur Bharaj, P.; Liu, J.; Phillips, A.; Park Rogers, M.; Zhong, Q.; Cesljarev, C.; Lloyd, K. Questioning Our Credibility: An Exploration of the Professional Identity Development of Mathematics Teacher Educators. Mathematics 2022, 10, 66. https:// doi.org/10.3390/math10010066

Academic Editor: Miguel

Ángel Montes

Received: 19 November 2021

Accepted: 22 December 2021

Published: 25 December 2021

Publisher's Note: MDPI stays neutral with regard to jurisdictional claims in published maps and institutional affiliations.

Copyright: (C) 2021 by the authors. Licensee MDPI, Basel, Switzerland. This article is an open access article distributed under the terms and conditions of the Creative Commons Attribution (CC BY) license (https:// creativecommons.org/licenses/by/ $4.0 /)$.
Abstract: Preparing future mathematics teacher educators (MTEs) with knowledge that are needed to effectively support pre-service teachers (PSTs) is very important. However, little attention was paid to MTEs' knowledge development, which is multifaceted and complex. This study investigates successes, challenges, and tensions that four international graduate MTEs and one mathematics teacher educator (TE) experienced in developing their identity as math teacher educators. In total, $20 \mathrm{~h}$ of interactive interviews were analyzed by using qualitative methods. Emerging themes include how MTEs establish a sense of credibility and how they feel they are navigating multiple identities. Among the graduate MTEs, credibility was described as having the following: (a) knowledge of and experience teaching in the US education system; (b) experience in teaching using a problem-solving approach; (c) the ability to enact theory in practice. While navigating multiple identities, graduate MTEs recognize their ethnic identities are central and influence their perceptions of self as MTEs, and how they think they are perceived by others. The results highlight the importance of understanding MTEs tensions and challenges and provide "in-the-moment" support along the journey of becoming teacher educators.

Keywords: mathematics teacher educators; professional identity; international graduate students; community of practice; recognition; credibility; third space

\section{Introduction}

The need to prepare teachers to effectively teach K-12 students is an important yet daunting endeavor. Despite this recognition of its importance, pre-service teacher education has not been without controversy. One aspect of the debate that has been more prominent in recent years is having common agreement across the mathematics education community about the knowledge pre-service teachers (PSTs) need to teach effectively [1]. Although there has been a lot of discussion and empirical work around mathematical knowledge needed for teaching in the K-12 school system, significantly less attention has been paid to understanding the knowledge mathematics teacher educators (MTEs) need to effectively support PSTs [2]. Undoubtedly, content and pedagogical knowledge are necessary, but not sufficient to effectively instruct [3]. The work of teaching is multifaceted and complex, and this is no different when it comes to instructing future MTEs. Undergirding this complexity are multiple cognitive and psychological processes (i.e., knowledge, beliefs, identity, emotions) that MTEs must navigate within their existing socio-historical context [3-7]. The field has advanced knowledge about how these constructs work in the lives of K-12 teachers; however, we still know very little about the development of MTEs. 
Cognitive and psychological constructs interact to inform and guide the decisionmaking and actions of MTEs, in particular, how MTEs conceptualize the role of a mathematics teacher educator, how they position or evaluate themselves within that role, and how that then determines their professional identity. Thus, professional identity is an amalgamation of beliefs, goals, and experiences across various social groups within both immediate and broader social-historical contexts [3]. How teachers see themselves as teachers informs what they do and say in job-embedded contexts (namely their instructional practices), and influences how they feel, their commitment, and their resilience when faced with professional challenges [8]. In fact, Richter et al. [9] found that teacher educators' levels of self-efficacy, job satisfaction, constructivist beliefs about teaching and learning, and use of more effective teaching strategies were rooted in their professional identity.

Identifying as a teacher reflects both how teachers perceive themselves (as teachers) and how they internalize others' (i.e., students, colleagues, and other stakeholders) perceptions of them as teachers $[5,10,11]$. Thus, the process of identifying as an MTE may be continually in flux, because the nature of "teaching" and the contexts in which teaching unfolds are continually developing and changing [3]. Given the role identity plays in how educators engage in the work of teaching, and how little we know about MTE's identity development, the focus of this paper is to understand factors that influence the process of identity development of a combined group of graduate MTEs and a faculty MTE who hold different cultural identities.

We draw on the [12] identity framework which foregrounds recognition, competence, and performance as central aspects of identity. In conceptualizing the identity development process of MTEs, we acknowledge that the work of MTEs centralizes mathematical knowledge for teaching teachers (competence-[13]) and the enactment of high-leverage practices (performance- [14]) with the intent of being seen as reflective practitioners and models of high-quality instruction (recognition- $[15,16])$. Thus, we find this framework particularly useful for exploring the identity development of graduate MTEs. Similarly to other work focused on examining the lives and work of MTEs (e.g., [17].), our study centers on the self-examinations of four graduate MTEs, three of whom are international students, as they progress through their mathematics education doctoral program. We specifically sought to answer the following question: What factors influence the professional identity development of MTEs engaged in a community of practice?

Our research extends existing work by showcasing the voices of international graduate MTEs with a range of experiences, as they attempt to understand their identity development within a community of practice with other TEs in their department.

\section{Theoretical Framework}

\subsection{Professional Identity}

We draw from multiple perspectives in defining professional identity. Kelchtermans [18] describes the concept of professional identity as "a lens through which teachers (educators) look at their job, give meaning to it and act in it" (p. 260). Mead [19] considered the concept of identity as a relationship with one's self. Similar to how an individual grows and develops, the self changes through interaction with the environment. Thus, identity is socially constructed [20] within communities of practice [21]. Professional identity development is shaped within cultural, professional, and personal contexts through interactions and embedded relationships with others [22]. This conceptualization is also captured in [23] four characteristics of professional identity, as follows: (i) an ongoing process of interpretation and re-interpretation of experiences, (ii) implying both person and context, (iii) consisting of sub-identities developed from the individual's experiences in different contexts and relationships which tend to harmonize, and (iv) where having agency is a key component, which means that individuals, in this case teacher educators, must be active in the process.

In essence, we identify with a variety of roles throughout our lives (e.g., student, teacher, friend). We also become members of particular groups that we may identify with 
(e.g., conservative, Christian, Chicago Bulls fan). Our experiences as we grow, and within these groups, occur within larger social-historical contexts, within which social identities emerge and reaffirm over time (e.g., race/ethnicity, gender, sexuality) [3]. In addition, we also align with and identify with particular personality traits which we tend to use when describing ourselves (e.g., I am generous, caring, smart, tall). Across the range of ways we identify, some identities are more foregrounded with respect to how we see ourselves and want to be seen. These identities are considered to be more central, where centrality refers to the importance of particular identities to an individual's sense of who they are at a particular point in time during their lives [24,25]. While pursuing a doctoral degree in a teacher education program, being a graduate student may be central to how students may describe themselves to others, want others to see them, and the perspective from which they interact with others. However, after completing graduate school, the professional role of faculty member and teacher educator may emerge as more central. As time passes and the individual continues to interact with the world in a range of ways, other roles may potentially become more central, such as being a university administrator, advocate or parent.

These multiple ways of identifying do not always cohere; instead, they may compete based on which is more foregrounded in our interactions with others and the world at a particular time. We refer to this more contextual and time-relevant foregrounding of particular identity as salience [25]. For example, in a university classroom, a teacher educator identity may be more salient during engagement in mathematical tasks or watching an instructional video. However, if students have not completed assigned pre-work or are reluctant to engage in classroom discussions, the teacher educator's ethnic or cultural identity, which is situated in different classroom norms and teacher and student roles, may become more salient. We draw attention here to cultural identity as culture shapes schooling, how teachers interact with students, and how they teach content. An individual's cultural identity is "ubiquitous" in nature, inseparable from their practice as a professional [26] Teachers bring their culture into the classroom, and with that cultural background comes influences on their expectations of and interactions with students [27]. As Beauchamp and Thomas [28] point out, "a teacher's experience can be one of not only active construction of an identity, but also of an imposed identity stemming from societal or cultural conceptions of teachers" (p. 7). Thus, teachers' cultural identity influences their teaching identity [29], and these cultural influences must be recognized to properly support quality learning experiences for international graduate students [30]).

In this regard, attending to what is currently unfolding in the classroom from the teacher educator lens may be replaced with the international student lens in determining the next statement or action [3]. Which identities are more central or which become more salient is dependent on a range of factors, including level of commitment to different roles, and the social-historical context within which interactions occur.

\section{2. (Mathematics) Teacher Educator Professional Identity}

Kreber [31] asserted that one's personal theories of teaching, perceptions of self and social and occupational contexts play a critical role in shaping one's identity. As Clemans et al. [32] mentioned, "While it is important to share the "what" and the "how to" of teacher education, we must not overlook the significance of "who am I" in this work" (p. 226). We attempted to understand what it means to be a teacher educator of mathematics by drawing on Carlone's and Johnson's [12] model as it integrates the following three components: recognition, competence, and performance, which play critical roles in determining discipline-related identity (e.g., science identity).

Recognition refers to how MTEs recognize themselves as teachers of teachers and how they are recognized as such by other stakeholders (e.g., PSTs, faculty, fellow colleagues). Recognition is centered on the idea that an individual cannot claim an identity all by themselves. It requires the acknowledgement and participation of colleagues, PSTs and faculty. In other words, "one cannot pull off a particular kind of identity unless one makes 
visible to others their competence in relevant practices and in response others recognize one's performance as credible" [12] (p. 1190). An individual's goal to become an MTE is situated within the norms, expectations, and standards of the academic community and what others conceptualize an MTE to be. Thus, professional identity incorporates both how the individual sees themselves professionally, and how this image of themselves is validated by others.

Competence captures the extent of a teacher educators' mathematical knowledge needed for teaching teachers, involving both content and pedagogical knowledge [33]. Performance relates to being able to draw on the full range of knowledge needed to teach in ways that reflect core practices for training PSTs. Combined, competence and performance are what [2] refer to as the mathematical knowledge needed for teaching teachers, which incorporates the knowledge of what, how and why related to both content and pedagogy, as well as the skill to deploy the teaching moves necessary to support PSTs' learning. There is no agreed-upon knowledge base for MTEs [2]; however, we know that at a minimum MTEs' knowledge and skill must match the knowledge and skills needed for teaching math to K-12 students. MTEs knowledge must go beyond that to understanding how PSTs engage with these ideas to inform the instructional moves they make or decide not to make, such as what questions to ask and when, what misconceptions students hold, or how to sequence tasks to minimize the development of misconceptions. Then, they need to utilize this knowledge they have about how PSTs learn and what they know to support them in connecting their own learning in university classrooms to teaching K-12 students [34].

Bergsten and Greyholm [35] suggested that a key aspect of teacher education is to support teachers in becoming reflective practitioners. Chapman [36] also considered reflection a key aspect of the work of MTEs where reflection involved "examining, framing, and attempting to solve the dilemmas of classroom practice; and being aware of and questioning the assumptions and values [they bring] to teaching" (p. 121). MTEs need pedagogical skills to leverage PSTs' learning to support connections between theoretical ideas and the practicalities of their roles in the classroom. In other words, MTEs must draw on PSTs' learning and engagement in instruction in ways that support PSTs in seeing how they can learn from their own experiences. Thus, MTEs must have a conceptualization of the continuum of teaching quality and be able to support PSTs in developing knowledge of characteristics of low to high instructional quality along this continuum, as well as how to identify and attend to them in their own practices.

The set of knowledge and skills MTEs need to attain credibility is vast. However, research suggests that a majority of MTEs in the US have little experience teaching students at the level of mathematics they are expected to prepare PSTs to teach (e.g., elementary school), and, for international MTEs, rarely does that include experience teaching students in a new educational context. Additionally, there are a range of different models of support for MTEs, but the majority receive little to no specific training to support their roles in their preparation programs or in their jobs [37]. Without essential training and support, there is the risk that graduate MTEs, both international and non-international, will have insufficient experiences to support the development of a robust professional identity in order to consider themselves credible MTEs.

The objective of this study is to understand the professional identity development of MTEs throughout engagement in a community of practice. To do so we focused our understanding on graduate MTEs' experiences and perspectives as they carried with them personal and professional biographies, institutional context, and personal pedagogies for teacher education that may influence how the learning experience unfolded, and their interpretations of the experiences (see also $[38,39]$ ).

\section{Study Context}

This study was situated within a larger project that sought to support mathematics and science graduate students (hereafter referred to as graduate TEs) in their development as teacher educators. The aim of this study is to understand the successes, challenges, 
and tensions graduate TEs experience through the identity development process. The project was designed to document and track the professional development of this group of mathematics and science TEs, who were members of a professional learning community called Community of Practice on Self-Study (CoPSS). Over the course of one academic year, two faculty TEs (one math-focused and one science-focused) met with eleven graduate TEs to discuss their ongoing teacher education experiences. We met eight times over the course of the academic year with each conversation lasting 2.5-3 h. Each monthly conversation was designed more as an informal social gathering. During the first meeting, we brainstormed topics and prompts that the graduate TEs considered salient to their experiences in their respective programs. For future meetings, we sat around a large table eating and discussing various prompts that we developed from our unstructured first meeting. Such prompts or topics included managing emotions related to teaching (e.g., anxiety), and teacher-student relationships, giving and receiving mentoring, methods of professional development for teacher educators, etc. These informal gatherings allowed the graduate TEs to feel relaxed and to show up as their authentic selves. This forum opened the door to some critical discussions where the graduate TEs felt safe to be vulnerable and to share their raw emotional experiences.

\section{Methods}

\subsection{Participants}

This paper centers the voices and experiences of one mathematics TE, Dela, and four mathematics education graduate TEs-Poorna, Jai, Kingsley, and Sandy. All five participants were involved in the mathematics education program at a large, researchintensive, Midwest university. The prospective elementary teachers (PSTs) they worked with in the education program were primarily white, female, middle class students. At the time of data collection, Dela was in her eleventh year of being a mathematics TE, all of which was at the same institution. She was an international person who identified as Black and had taught high school math in the US and Jamaica, before pursuing graduate school. Despite her years of experience teaching math content and methods courses, and identifying as a mathematics TE, engaging with PSTs in the math methods course was a consistent challenge.

Poorna was in the fourth year of her graduate program. She had taught middle- and high-school in India before pursuing graduate school in the US. She got a chance to teach both math content and methods courses for the elementary education program during graduate school. Based on her teaching experiences in the US, she was uncomfortable calling herself a TE, but self identified as a researcher and aimed to sharpen her research skills during the program. That being said, she still identified herself as a loving schoolteacher within the Indian education context.

Jai identified herself as a first-generation, Asian female graduate student who studies, researches, and teaches in the US. As a child, she was assigned to tutor her classmates in math, beginning in fourth grade. Jai had provided one-to-one math tutoring to dozens of struggling students, with positive results not only in terms of their mathematical achievements but also general well-being. From these experiences she developed a strong, positive identity as a math teacher. While teaching math content and methods courses in the US, Jai set high expectations for PSTs' learning, as her math teachers had done for her in China. Jai experienced a range of cultural conflicts, which challenged her TE identity.

Kingsley identified as a Black male from Jamaica, who had taught high school math in Jamaica before joining the graduate program in the US. During his program, he was assigned to teach elementary methods, content, and problem-solving courses. He held the view that having effective discourse in the classroom is key to promoting student engagement and learning opportunities. He had a strong commitment to teaching and was passionate about preparing PSTs to teach students mathematics effectively.

Sandy, a white American woman, joined the graduate school as a shift from her prior career as an engineer. Although she was being trained as a TE, at the time of the study she 
was teaching a remedial class in the mathematics department to support students in advancing in their programs. She self-identified as a collaborative teacher focused on supporting learners who have been historically disregarded academically for not understanding the mathematical meanings behind the abstract concepts.

Although we foreground the experiences of the math teacher educators, it is important to note that CoPSS also included one science faculty TE, Megan, and five science education graduate TEs who participated in the same conversations as the mathematics teacher educators described above; thus, their voices were integrated with the mathematics teacher educators' voices throughout the CoPSS discussions. The science TE was a white female who identified as an international person. One science graduate TE was a white male (Adam), one was a Chinese female (Zola), one identified as an African American female (Jesse), and two were white females (Ally and Christy). In the data analysis section, we describe how we were able to tease apart the experiences of the math TE and graduate students from the science TE and graduate students, while honoring the essence of this collaborative learning experience.

\subsection{Data Sources and Analysis}

Data sources included approximately $20 \mathrm{~h}$ of conversations recorded during CoPSS meetings. In these conversations, which took the form of interactive interviews, each participant was both researcher and participant. Interactive interviews are an approach to autoethnography, a research methodology that seeks to describe and systematically analyze personal experience to understand cultural experiences [40]. These interviews provided an "in-depth and intimate understanding of people's experiences with emotionally charged and sensitive topics" [41] (p. 121). The collaborative nature of CoPSS engaged the participants in research activities (i.e., thematic discussions each meeting) where everyone unpacked personal and collective issues as they unfolded through conversation. As professional identity is shaped by and influenced within communities of practice, the context and the use of these interactive interviews supported both the data collection and identity development of the participants.

The conversation from meetings in each of the eight months was assigned to a pair of coders (i.e., CoPSS members), who were responsible for transcribing and analyzing the conversation for that month. After the recording was transcribed and transcripts read, all the coders met to discuss what they thought was the central focus of each month's conversation. The ideas were condensed into themes and included in Table 1.

Table 1. Themes generated in first coder conversation.

\begin{tabular}{|c|c|c|c|}
\hline Month & Theme & Month & Theme \\
\hline September & $\begin{array}{l}\text { Positionality: Identity shifts in navigating } \\
\text { teacher education }\end{array}$ & January * & Marketability as a Doctoral Student \\
\hline October & $\begin{array}{l}\text { Honoring Individuality in Teacher } \\
\text { Education }\end{array}$ & February & $\begin{array}{l}\text { Meeting Expectations of Students: The Role } \\
\text { of Feedback }\end{array}$ \\
\hline November & Measuring Teacher Educator Success & March & Explaining Concepts vs. Facilitating \\
\hline \multirow[t]{2}{*}{ December } & Struggle between theory and practice & April & Navigating Making Mistakes \\
\hline & & May & $\begin{array}{l}\text { Understanding the Contextual Influences } \\
\text { on Teaching }\end{array}$ \\
\hline
\end{tabular}

* January's recording was not clear, so this data was excluded from analysis.

After this conversation to discuss initial thoughts about the transcripts, coding pairs then worked together to conduct a more detailed and focused analysis. Each pair inductively analyzed their assigned transcript, using an open coding process where codes were focused on capturing the MTEs' experiences relating to their recognition, competence and performance as TEs [42]. Open coding is an analytic technique where concepts (or terms/phrases) are attached to the observed data (e.g., statements in transcripts) and phe- 
nomenon. Each pair coded the transcripts using a range of software, then they tabulated the codes and reflective quotes in an excel spreadsheet. After transcriptions were created, read, and initial analyses done, each participant had the opportunity to provide feedback on the interpreted meanings to verify if they aligned with what was intended. This process of member checking supported trustworthiness of the study.

With this initial coding process completed, all group members came together to discuss the identified codes across the different transcripts and collaboratively worked to collapse codes to identify themes that captured the salient experiences across the teacher educators' journeys. We focused on developing themes that captured the explicit and implicit meanings across the codes. In Table 2, we provide examples of the codes developed, and themes and sub-themes that reflected the convergence of these codes.

Table 2. Examples of Themes and Codes.

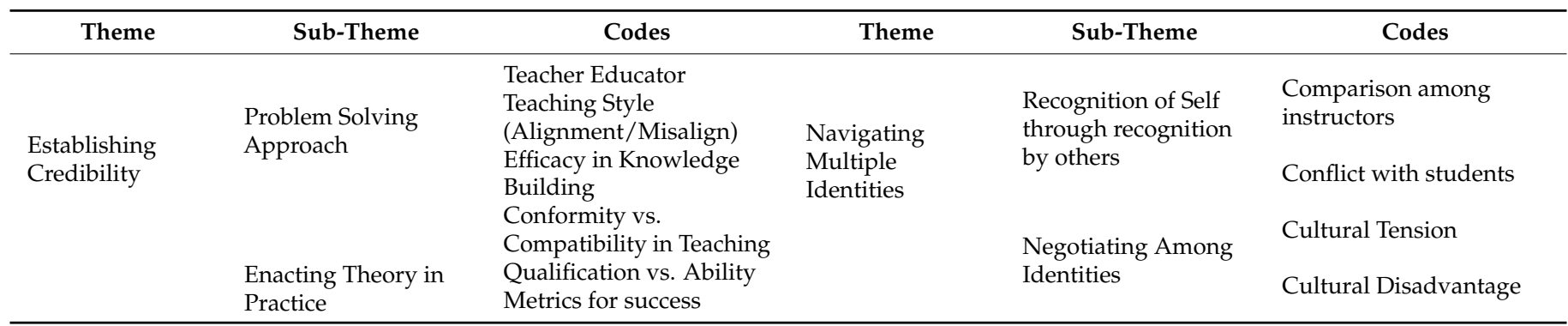

This process of discussion and collaboration allowed us to gain clarification, verify our interpretations and come to consensus around the meanings we drew from the data which supported rigor in our analysis process. After the identification of themes, each pair returned to their assigned transcript to look for specific examples in their prior coding associated with each of the themes. With these examples, we met to develop a consensus document of examples under each theme to identify specific patterns in the conversations across each of the themes. We also discussed the ways in which codes and themes developed in the detailed analyses (Table 2) aligned with the initial themes generated (Table 1). For example, the sub-theme Enacting Theory in Practice (Table 2) aligned closely with themes Struggle between Theory and Practice and Explaining Concepts vs. Facilitating (Table 1). This alignment across codes and themes verified that our interpretations were grounded in the data. With the consensus document as a guide, we completed a final synthesis discussion examining the nuances of the examples across themes. From this discussion researcher memos were developed of the core ideas presented in the consensus document. We also selected one-tenth of the codes along with the data they represented and had an external researcher develop themes. The result showed close overlap with the existing themes. The iterative and collective process employed for data analysis helped to establish trustworthiness in the results of this study, as through this process we considered "multiple perspectives, multiple interests, and multiple realities" [43] (p. 575).

As the study was targeting the experiences of the MTEs, we foregrounded examples from the conversations that captured the voices and experiences of the faculty MTE and graduate MTEs. We were mindful in the telling of these stories through conversation that members engaged in turn-taking as we constructed a collaborative narrative. As such, members shared their thoughts and descriptions of experiences, then others responded with comments, questions, or the telling of a similar or connecting story. Because of the way these conversations unfolded, it was not possible to fully isolate themes that reflect the experiences or voices of only the MTEs. Thus, in what follows, we describe the themes that center the identity development of the five MTEs and foreground their voices from the data. As these experiences were shared within the context of discussions with our science education colleagues, we include their dialogue in order to provide the reader with an in-depth understanding of the identity development experiences of the MTEs. 


\section{Findings}

From our analysis, two main themes emerged associating credibility and navigating multiple identities. When giving credit to excerpts, we have used pseudonyms to help distinguish between the author participants and the other science education colleagues, and to maintain the anonymity of the participants.

\subsection{Establishing Credibility}

Teacher educators navigate two distinct communities-one includes prospective teachers and the other involves the higher education community. It was important for these MTEs that they were seen as credible in both communities. This aspect of recognition within these communities was essential to developing a TE's identity [12]. However, achieving this credibility was a significant challenge because of the context in which this group of teacher educators were situated. They felt that within this context, being a person of color with an accent, which described four of them (excluding Sandy), automatically put into question their credibility by the PSTs by the prospective teachers [44]. Among the MTEs, credibility was described in three ways, specifically in terms of an MTE having the following: (a) knowledge of, and experience teaching in, the US education system (e.g., curriculum, schooling norms, etc.); (b) experience in teaching using a problem-solving approach; (c) the ability to enact theory into practice. Each of these descriptions is elaborated on below with supporting dialogue from the community of practice discussions. Therefore, there are times when comments are included from the science education community members to provide context for the MTE comments.

\subsubsection{Knowledge of, and Experience in, the US Education System}

Although graduate school is designed to be a learning experience, the four graduate MTEs came to believe there were prerequisite knowledge, skills, and experiences necessary to effectively support PSTs in their development as teachers of mathematics. The international graduate TEs also felt they were particularly disadvantaged as much of this knowledge could not be easily procured outside of having been students or teachers in US schools. Zola commented on the ways in which students are encultured into schooling in the US and that although the difference with her own culture can be stark, she endeavored to focus on students' learning. Zola stated,

"Like I recognize that there is a way that they [students in US] have been encultured in schooling. And that's different from my experience, but my goal again is for them to learn and to find value in the class."

One cultural difference within the classroom the international graduate MTEs noticed was the teacher-student relationship in the US compared to their own learning and teaching experiences in their home countries. When asked about building connections with students in India, Poorna was specific in describing the ways in which teachers and students interact in her culture and how not understanding these new norms posed challenges in her US classroom. Below is an excerpt from a conversation with the science TE, Megan, and Poorna about how she built connections with her students in India.

Megan: "Can I ask you a question? When you taught like kids back in India, did you feel like you had that connection that you needed in order to be able to talk to them?"

Poorna: "Well, I was expecting I'm going to share my teaching stories and I felt I could share my pictures with my Indian students to PSTs. In India, I had a really lovely bond with them. I had the connection and never wanted to be a strict teacher. I gave them [students in India] a space where they used to talk. I used to talk, we used to have general conversations not only around mathematics."

However, as Poorna noted, when she tried similar approaches of making personal connections with her PSTs in the US context, they were not as well received. 
"I got feedback from my American friends saying try to interact with them [PSTs]. So, I used to talk with them [PSTs] about Indian festivals or share my pictures. I really tried to involve them, but still there was a difference. I don't know why, but there was a difference that I can't figure out. At times, like you had those Halloween jokes or anything, I don't know, I have to ask-'do we say Happy Halloween?', 'Is it a norm to say?' ... So I lacked something culturally, and I don't know how to interact. And for me as an emotional person, I'm really in trouble, it's really hard to make that connection. And without the connection. I really can't teach the way I want to teach."

It was visible in Poorna's conversations that she struggled to grasp the norms of classroom engagement that PSTs in the US would connect with. Not being able to build that rapport impacted her ability to teach for which she had a strong negative emotional response. Her notion of being recognized as a person and as an MTE by her PSTs was a significant determinant in how she viewed herself as a credible MTE. Poorna's experience, while nuanced, resonated with the other international graduate MTEs. They expressed that it was not just the feeling of being connected, but another struggle was helping PTSs recognize that even though their prior teaching experiences were not in US classrooms, they were still valuable examples they could learn from. For the graduate MTEs, this struggle was compounded by their own self-doubt as to who they are as educators of teachers of mathematics, which made them question if their experiences were in fact valuable to draw from. This uncertainty was visible in Poorna's experience (described above) where she tried to share aspects of her culture and her own experiences, but they were not embraced by the PSTs.

Another idea that came out of Poorna's statements was that unawareness about cultural contexts not only impacts making relations with others, but also influences how one interprets the meaning of professional responsibilities-whether it is specific teacher student relationships or making sense of documentation in a new context. Dela realized that one of the reasons Poorna would be reluctant to share her Indian classroom experiences is because her definition of 'teacher-student relation' is different from that of her PSTs. Dela stated,

Dela: "So, and I know this because Poorna and I grew up in a very similar kinds of culture because we were colonized by the British ... our orientation [as TEs of color] to what a teacher should be and even the teachers who we liked in school and really respected is very different from the model of a teacher that a white female preservice teacher would identify as a teacher they'd likely respect. The teacher who I adored when I was in high school was very strict, but he was, he knew everything, and he was so amazing. Um, and I just love that. Right?"

Christy: "So there's a difference between, because I've had teachers like that who I respect but I don't know if I liked. That's the difference."

This interaction indicates there is a difference in how 'good teacher' is defined. By not acknowledging these differences, we tend to create unspoken disconnects between what an international TE brings with them, and they are expected to show up to teach in their roles as MTEs.

A distinction should be made between lack of familiarity, or not knowing about something, and not understanding the cultural meaning. Cultural distinctions are present not only at the societal level but also in the way meanings are interpreted. A common aspect of university curriculum, the course syllabus for example, might have a different level of significance in different settings. Poorna was familiar with the idea of the syllabus, but was unaware of how integral it was for how a course was organized in the US. She described her experience with this realization in the following quote:

... syllabus in the US context is like once it is written, it becomes a policy, that would be considered as the final word. That was not the same in India. We never had that type of structured syllabus. It was just a set of topics. Uh, so I learned 
one thing in my math content class in the US that the syllabus really matters a lot. Some of the things that we take for granted, cannot be taken as such. Um, we have to be very explicit about those things in our syllabus and tend to abide by those just to maintain that fairness for everybody.

Poorna's experience with a syllabus in an Indian context was that it was fairly informal and not rigidly adhered to with respect to how the course was taught or performance evaluated. However, this stood in stark contrast to the design and use of the syllabus for courses she was experiencing in US universities, which went beyond just a set of topics but also tended to include a weekly schedule, descriptions of assignments and grade allocations. More comprehensively the syllabus served to clearly articulate connections among content, learning outcomes, assessments and instructional practice. Megan, who had previously worked with an Indian science graduate TE, also shared that these concerns are not unique to Poorna because her former graduate TE experienced a similar realization when she first began her doctoral program. Poorna noted further in her discussion with the CoPSS group that she felt such cultural interpretations put us (international students) at a disadvantage in the professional US setting and made them question their competency in developing academically important documents, such as a syllabus, in the future.

\subsubsection{Experience Teaching from a Problem-Solving Approach}

For Poorna and her other international colleagues, the issue of not having experiences as a learner in the US and with less student-centered mathematics instruction led to a sense of self-doubt about the quality of her content and pedagogy knowledge. Poorna, for example, described the emotional burden in having to quickly learn to teach using an approach she had never experienced firsthand.

"So the way they teach [in the US] is entirely different from the way I teach... How well are we [TEs] prepared to exhibit all those traits that we want our PSTs to actually do? Because everybody knows I'm coming from a really direct instruction environment, all these things are really new to me. So to learn it, implement it, and expect my students to do the same. This is like a huge trajectory to accomplish within a period of four months ... This causes emotional burden because someone else from outside might have doubted that I'm not doing a good job in my teaching."

In the excerpt, Poorna expresses her thoughts on her significant learning trajectory to teach in more student-centered ways and her concerns about how others will perceive her teaching as she continues to grow. Her inexperience with these teaching methods made her question her own credibility as a MTE, to which she tried to compensate by developing herself as good at research instead. She said, "I don't feel confident to talk about myself as a TE as far as my teaching is concerned, so I tend to be better at research. I want to compensate in some way so that if I'm not good at teaching, I should do something else".

In response to Poorna's doubts, Adam, a science graduate TE offered another perspective. Adam approached the idea of a negative experience as something to learn from, emphasizing that it is not the amount of experience or the right kinds of experiences that is important, but it is how you reflect and learn from those experiences. We note here that Adam is a young, white male in the fourth year of his program at the time of this study and perhaps had the most experience of all graduate student participants with teaching methods classes. Therefore, it is perhaps not surprising to hear him say,

"What I've come to know about being a teacher educator is that you're always learning while also teaching ... Like what could I do better or what could I do a little bit different? That is what I'm reflecting on. And then next for me is just to continue to be reflective as I teach next semester. And if I'm teaching the same class, see again what I can do differently or how I can challenge the pre-service teachers more given my increased experience." 
Adam had expected that his limited experience with classroom teaching was not going to interfere with his development as a teacher educator. Although he concurred with his peers that he felt at times the pressure of presenting himself as credible when he was himself still grappling with learning to model some aspects of effective teaching, he held true to his professional identity of being a reflective practitioner. Therefore, from the CoPSS discussions such as this one between Poorna and Adam, the TEs realized that having negative experiences in one aspect of their doctoral program is not a reason for ignoring their development in that area by directing their attention solely on a different aspect of their professional development. In the case of Poorna, she saw developing herself as a high quality researcher as a way of compensating for the deficiency she felt existed in her teaching.

Connecting with the notion of learning from experience, Sandy shared how sometimes learning to teach is bumpy, and that forward movement is not always straightforward. She described an interaction with a student that began with Sandy trying to guide the student's thinking but quickly evolved into Sandy showing the student the solution. Although her more direct approach was not a preferred method, Sandy observed how the student was able to use what he had learned to support others. Sandy explains her dissonance in how she is feeling with this example in the following quote:

"I was tutoring one of my students [who] was so super frustrated about this problem in finite [math]. He was so frustrated by it that he needed to know and so I told him how to do it. So then I said, now tell me what you know. And so he repeated every step back to me and then went on to teach everybody around the table how to do that problem. So it was kind of like I directly instructed that one [student] but there was a benefit. And so I think that it can happen that way as well. Even though I'm really experiential in my philosophy usually. I don't know. I'm all over the road."

Sandy described how sometimes she falters when trying new methods of teaching and that these attempts have often been unsuccessful. For example, she described one of her first attempts to incorporate the Five Practices to frame mathematical discussions in her class [45] and how challenging it was for her that she abandoned the approach midway.

"I tried doing five practices last semester, and it just messed me up so bad that I abandoned that methodology for now, because I just needed to go back. And I think that is because I tried to change too much at once, which is something you're not supposed to do. But I practice these basic principles, but not exactly according to the methodology, the five practices. Exactly. So I'm still a little scattered."

In higher education, MTEs are immersed in a culture that promotes a problem-solving approach to mathematics teaching and are exposed to a range of instructional strategies to teach in this way. Trying to incorporate multiple strategies without appropriate coordination is risky and can result in disorganization as Sandy experienced. Additionally, Sandy's experience of feeling scattered may be a byproduct of the internship she was required to complete in order to prepare for teaching the course. During the internship (described above), graduate MTEs learn about best practices in teaching and observe faculty MTEs model these practices in the courses the graduate TEs will eventually teach. Graduate TEs are often amenable and adopt these ideas into their instruction without perhaps fully understanding the nuances and complexities of these instructional approaches in the US classroom. This begs the question of how to design apprenticeship experiences for graduate TEs to support the translation of educational theories into their practices? Do these experiences need to be different for international graduate MTEs given some of the cultural differences Poorna and Jai previously described?

Once again, Adam, a science grad TE nearing the end of completing his degree, tried offered these words of advice to his peers,

"It's difficult, right? Because you still have to be confident in what you're doing and know that you're not an expert at what you're doing, but not so self-confident 
that you're not willing to take criticism ... that you just think everything you're doing is right...you have to be reflective and critical of what you're doing."

In other words, Adam was trying to clarify for his peers that credibility comes not just with experience but reflecting and learning from those experiences. Poorna's, Sandy's, and Adam's experiences are highly contextualized within their prior teaching-learning experiences. The range of experiences suggest that graduate TEs' learning trajectories are highly individualized; hence, a one-size-fits-all approach may not be best for their training. Their opinions also show how one recognizes themselves as a TE, and the role credibility plays in identity development.

\subsubsection{Enacting Theory in Practice}

Reflective of the wider mathematics education community, a constructivist view of learning was the central theory of learning that was promoted within the mathematics education program at Ishowa University. It is both tacitly and explicitly communicated to graduate students that the community has moved beyond the transmission view of learning and promotes the notion of mathematics learning involving students actively engaged in 'doing' mathematics. Thus, instruction should be designed to support the mental processes of creating, exploring, testing and verifying. Additionally, taking the perspective that learning is both an individual and social process, students should be encouraged to work collaboratively to explore, generate and debate conjectures, solve problems generated from their own explorations, and construct personal meaning from all these experiences. As previously mentioned, all courses within the mathematics education program at this institution were designed to be taught applying, or promoting, a problem-solving approach, and graduate MTEs are required to complete an internship with a faculty member teaching the course prior to teaching the course. As a part of the internship, graduate students must attend all the classes and observe the faculty member instructing, which should serve as a model for experiencing reform-based instruction and learners (PSTs) "doing" mathematics. As a condition of the internship, graduate MTEs were required to teach 1-2 lessons during the semester. Although the internship experience, which included observing faculty and peers instruct the courses, and having access to the course materials, supported the graduate MTEs in preparing to independently teach, it also engendered anxiety and feelings of inadequacy.

Having experienced more traditional forms of learning themselves, the graduate MTEs doubted their ability to enact these teaching principles in practice. There seemed to be no rules or specific guidelines to follow about how to organize the lesson to engage students meaningfully. There was no manual to consult for organizing the lesson or to evaluate how well the lesson unfolded. The graduate MTEs' search for more tangible guidelines is reflected in Kingsley's response during an exchange with Megan, the science faculty TE.

Megan: "If you think meaningful discussion in really deep interrogation of the ideas, and this is important, and you only get through three of the five problems that are set up, is that a measure of being more successful to you than if you had not had as deep discussions but you got through all five problems? I think that's what you have to kind of think about. What do you feel is the point of importance to you?"

Kingsley: "So, [are you asking] do we have a general guideline to work with? Because, I must admit that I have had a challenge in connecting theory about problem solving with my own teaching. As Jai mentioned earlier, in the geometry course that I taught during the course of last semester. I really struggled! To think deeply through a particular task in such a way that it would be able to help the students in engaging with a certain mathematical concept in a meaningful manner ... and then to respond to the students' thinking so it would push them to even think more in-depth about the concept." 
During the conversation, Megan began with framing what identifiers might be used to determine if a discussion is meaningful. Then, she discussed how having these criteria might be used to determine how a teacher might evaluate the quality of a lesson in cases where the lesson did not unfold as planned. Although this made sense to the graduate TEs and aligned with much of what they had discussed in seminars and during the internship experience with faculty members, as Kingsley expressed in his questions "Do we have a general guideline to work with?", tangible guidelines on how to instruct in student-centered ways were desired. What was not transparent to the graduate TEs was how and when to make these kinds of instructional decisions (i.e., when to reduce the quantity of work to optimize quality of learning), and this uncertainty was internalized as lack of competence, as an inability to enact theory in practice.

The graduate MTEs also described struggles in having to effectively utilize emerging knowledge about PSTs they were teaching to inform instructional decisions in the moment of teaching and also during planning. One particularly salient skill that was challenging for graduate TEs was extending PSTs' thinking about content or teaching without revealing the responses. Teaching with telling was conceptualized somewhat as the primary indicator of a transmission model of teaching, thus any incidence of what was perceived as telling was considered failure to teach in student-centered ways. In the following excerpt, Poorna explains how she interpreted these instances.

"Let me tell you why it means that there is a knowledge gap for me. It means that I have not unpacked the student's learning trajectory in a way that I can meet the student and his or her need in order to create a space where they can make sense of this idea. I guess the reason why I'm pushing us to really unpack this is that I think I've come to the point where if I have to tell a student what I know, then I see it as a failure on my part."

Both the science and math TEs provided alternative perspectives on how to conceptualize constructivism and student-centered teaching, emphasizing that there is not one right way to instruct.

Dela: "there's one thing that you [Megan] kind of touched on, which I thought was interesting, when you said, well, learning happens in a bunch of different ways. So, when we think about constructivism, you think it's a very clearly defined way of teaching. That's not really the case. It's not a description of a teaching approach. It's more a philosophy about learning. If you're thinking, well, actually people learn stuff in different ways and in different contexts then my goal is to try to help them to really learn and make connections. I need to try to make sense of this space that we're in, and what our tasks are and decide what is the best way for them to learn this stuff. So it might be that your students need a bit more guidance or you may have to highlight for them some things in their thinking, or present some basic ideas so they can grasp some more complex ones. It's important to consider the students, the content and the context."

Megan: "As someone with 20 plus years of teaching [in the classroom and higher ed], it's unrealistic to compare yourself to me. I mean you're working with all kinds of various levels, and my work and understanding, my measure of success with PSTs is going to be very different than yours. I think that we must consider and understand what our ultimate goals are, what we want people that we're working with, our learners, whoever they may be, undergraduates, classroom teachers, preservice teachers-what we want them to learn."

Some key points that these two experienced faculty TEs tried to emphasize were that that quality teaching varies in what it looks like when implemented. Key considerations for instruction are the students, the content and the context and that the measure of success should relate to what you want your students to be learning and what you are doing to support your students in making the necessary connections to achieve that learning. Thus, 
it is unrealistic for graduate TEs to compare their teaching with more experienced faculty TEs because the contextual conditions under which we teach are not fixed.

\subsection{Navigating Multiple Identities}

For the graduate TEs, their ethnic identities were very central and influenced their perceptions of themselves as TEs and how they thought they were recognized by others. These experiences are encompassed within the following two subthemes: negotiating among identities of researcher, teacher, and ethnic identity, and recognition of self through recognition by others

\subsubsection{Negotiating among Ethnicity, Personal and Teacher Educator Identities}

Although the international TEs had some exposure to US education culture and the society more broadly, they identified very strongly with their national and ethnic backgrounds. On entering the classroom, they did not leave these identities behind; thus, they tried to navigate their roles as emerging TEs with their perceptions of who PSTs should be in the classroom. PSTs also have their own ways of being in the math classroom developed over years of schooling. They also have ideas about who their instructors should be and expectations of the teacher-student relationship. Tensions arose in instances where the perceptions of roles held by the graduate TEs and the PSTs did not align. These tensions were most visible with respect to grading and PST's cognitive engagement, and the implications of these for feedback and course evaluations.

Grading and assessment was an area that several of the graduate MTEs and faculty TEs in both mathematics and science found challenging to navigate, and particularly with respect to the perspective many of the PSTs held for extra credit. Megan described what she thought grades should reflect and why extra credit ran contrary to that principle.

"I want to make sure that the grade that they're getting in my class, yes, I truly believe as reflective of what they know or are able to do, know and are able to do. So when they ask to do extra credit that's not telling me that they actually know how to teach science better. It just means that you went and sat in a talk and got some extra points. While I encourage them to go to those things, I don't give extra credits for them. I try to explain that to them it's important for me that if you want to get the " $\mathrm{A}$ ", if you want a much better grade, then you're gonna work hard and I'm going to be there to help you and we're going to work together to get you there. You're not going to take the easy route.... I try to convince them quality and effort really do matter."

Jai extended this perspective adding that although she wanted students to get good grades and feel happy about what they learned in her class, she felt that she needed to be a gatekeeper of the grades. In taking on this role, she could better ensure that their high GPAs reflected what they knew. As Jai noted,

"Although in the US, the [evaluation] policy does not use students' grades to reflect your [the instructors'] teaching quality, I realized myself, like I told Dela before, felt sad when I saw the students did not meet the high expectations and get high grades. I felt sad. I feel bad about myself and my teaching."

Jai considered grades reflected the level of students' learning outcome so when students achieved a low grade, she thought it was her responsibility. This may be rooted in her own Chinese educational culture where teachers considered students' achievement as an indicator of their teaching quality. However, in China, students' grades were generated based on standardized tests and rigorous grading. Teachers from the same schools or the same cities grade the same tests based on one rubric. However, as a TE, she had the freedom to create the assignments and the flexibility to develop the rubric to grade the assignments. Jai experienced tensions between whether to grade conservatively or liberally as she took into consideration how grades might influence PSTs' emotions and attitudes towards math. She explained, 
"One time I felt sad about giving students good grades. So, on one hand, I want to give a good grade to the student. Like I can find some parts to give points which will increase their grades. I want to give them good grades because I do not want them to feel afraid of math and I want them to have a good feeling with math. But, at the same time, I feel shameful if my students who graduated and are on the job market, and people see this student got A + in my geometry class. When others see this, they will doubt our [institution's] education quality which will eventually ruin the good reputation of our institution."

Jai experienced the grading tension as a graduate MTE. The tension caused by the multiple role grades played in her value system. Jai considered a high grade to be a motivator for PSTs, an indicator of her teaching quality, but she struggled with this alignment between grades and PSTs' actual knowledge and skills with respect to how it might impact the reputation of the university.

From Jai's perspective, foregrounding PSTs' growth and development in some ways seemed to run counter to attending to their psychological and emotional well-being. This was reflected in the identity tensions experienced around grading, that is, grading conservatively to authentically reflect PSTs' disciplinary and pedagogical knowledge and skill versus grading liberally to support pleasant emotions around mathematics-focused engagement. Similar tensions arose for the graduate TEs related to PSTs' cognitive engagement and effort. Although they did not believe that effort automatically led to high-quality work, they expected students to expend significant effort in trying to make sense of course content and in completing assignments. Expending effort included paying attention in class, actively engaging in problem solving in and outside of class, and utilizing the help resources available (e.g., office hours). Therefore, complementing Megan's earlier perspective, Jai shared her observations that PSTs often do not try or put in sufficient effort and that responsibility lay solely on them.

"Um, I think based on my personal experience and maybe my cultural influence. I see effort play a huge role in learning. So, when my students do not meet my expectations, I generally think it is because they did not try their best."

Additionally, Jai shared some of her frustrations with trying to make herself available to support her students, but they just do not seem to make a similar effort,

"I always expect some students to come to my office hours. You know, students are so different. They are at different levels and you cannot be responsive to all of them at the same time. I really hope some people come to my office hours and work together to address their questions. I even tried hard to invite them, but very few came."

Following up on Jai's comment, Dela, the mathematics faculty TE, also had experiences of students not exercising due diligence to grasp the concepts. She explained,

"I tell them (PSTs) obviously the hour is there, but just let me know whether or not you're going to come. Cause in the 11 years that I've taught here, I think maybe I've had five students come for office hours. Usually you have to ask them to come, even when they did poorly on an assignment, I still have to beg them to come to office hours. But when the final exam is close, and the day before the last class when they look at their grade they say, what can I do for extra credit?"

In her multiple years of teaching, she only had a handful of students who ever came to office hours even when they were specifically asked to do so, or when they were performing poorly in the class. Despite feeling that the PSTs should work hard and that grades should reflect their PSTs' knowledge and skills, Jai was also aware of the potential negative implications of being true to her identity as a Chinese teacher, in that she may receive negative evaluations for her honest feedback which made her fearful.

Additionally, Poorna highlighted that these interactions with students were increasingly complex because they challenged who you were as both a person and a professional. Poorna passionately wanted to be a good teacher to the PSTs, she worked hard preparing 
and thought deeply about how to build personal connections that would create an engaging and supportive learning environment. She wanted this work to be valued and appreciated. She questioned if that was even possible.

Poorna: "Will I ever get to the point where I have done enough where everybody is happy with me and my work?"

Sandy: "Poorna's words resonated with me. I think that's one of the most important messages for me personally and that we give to our teachers. Um, but they're never, because we're in this role where we're challenging people, we're never going to please everyone and we're never going to be in a frame where everybody's happy with us because we're challenging people to grow in ways that they may not be comfortable with, especially with the Five Practices. I think it's not a realistic goal and I have to keep reminding myself of that."

Sandy pointed out that while she connected with Poorna's sentiments, they may be unrealistic, in that, in her role as a TE in the contexts in which we teach, essentially, she was expected to consistently challenge the PSTs and engage them in cognitive struggle in efforts to help them develop. Unless the PSTs understood and appreciated these objectives, sentiments of value and appreciation from the PSTs were idealistic.

\subsubsection{Recognition of Self through Recognition by Others}

Being recognized by others, primarily faculty and PSTs, as a competent teacher educator was very important to the graduate TEs. However, for the graduate MTEs the idea of recognition involved being acknowledged as an MTE in both personal and professional ways was important for how they viewed themselves as TEs.

Poorna described the unpleasant emotions she felt when she saw how her PSTs responded to and acknowledged another graduate TE.

"I feel overwhelmed since yesterday. I had students, the same group of students in my class, and I never, I never had that relationship with them. That same set of students were in class, the same set of students are in our next class with some other instructor, the way they interact with [another MTE], and that other instructor, who is also American, it's so different. I don't, I don't know, I really want to fill this gap. And that hurts me. That hurts me when they pass that they don't talk. I just feel bad, and I don't like this gesture at all."

Though Poorna is trying to work with her PSTs by ascribing to new skills and expertise appropriately, she feels she is at a disadvantage, which she explicitly connects back to her inexperience in the English-speaking environment or because of cultural deficit. Poorna knows building rapport with students is important for creating a valuable learning environment; however, she felt overwhelmed knowing that despite her efforts she was not being successful (at least in her mind). She internalized this deficiency personally but also as a failure as a teacher educator to establish a warm and healthy relationship with her students.

In response to Poorna's concerns, Dela described the ways in which she had to suppress aspects of her own personal identity in efforts to connect with students in ways that they could see her as their teacher which she believed would influence their ability to learn.

"And so, it was now a mental process of thinking about, well, how do I become the teacher that they need me to be in order for them to be successful? ... Here's the shift. I had to learn like, what do white suburban Midwest girls, what are they interested in? What are they like, um, how do they connect? Because connection is really important, right? Um, especially when they're seeing someone that doesn't really look like them and clearly doesn't share history, culture, really anything. Um, and so again, I shift and I change, um, to be the teacher that my students need me to be. And so that has been, it's been challenging, but it's been rewarding. And I can't say that's everybody's philosophy about teaching, but 
that's my way of serving my students and making sure that the goals that I have for them, and I think the goals that they have for themselves kind of align."

Dela described how she separated aspects of her personal identity to shape a professional identity that she felt would allow for the best environment for her students to learn. She described how trying to understand the issue from the perspective of PSTs helped shape who she is an MTE-a teacher prioritizing the needs of her students.

\section{Discussion}

The role of MTEs in preparing PSTs to effectively teach mathematics is essential yet complex. We observed that being recognized as an MTE, and the source of this recognition, matters when it comes to how MTEs identify with the role. In this study, the MTEs perceived that recognition as an MTE was based on how others determined their credibility. This idea of credibility is, in their eyes, related to how well their teaching reflected a problemsolving orientation, as mathematics education faculty have suggested is important, and how well they were able to develop rapport with PSTs. Additionally, the graduate MTEs felt credibility, as it relates to competence and performance [12], could be achieved with learning to successfully navigate the US university classroom context. The complexity of navigating their personal social-historical contexts can be difficult when entering a new national and cultural context [3-7]. The international graduate MTEs experienced cultural conflicts between the teaching and learning they had experienced prior to beginning their doctoral program, and the teaching and learning that was the expected norm in their new US context. Poorna and Jai discussed the cultural differences regarding the purpose of a syllabus, and how these differences impacted their feelings of competence as they navigated those differences in understanding. Cultural conflicts also manifested for Poorna in her desire to connect and build rapport with PSTs. Establishing these relationships proved difficult when PSTs did not respond to the cultural connections Poorna presented in class or did not appear to value the experiences she had to offer from her classroom teaching India because they originated outside the US context.

The graduate MTEs felt the quality of their performance as MTEs was grounded in their ability to enact student-centered strategies in the classroom. Sandy felt tensions when deciding on whether to provide her students with correct answers versus allowing them to struggle. These struggles to employ student-centered strategies also manifested as a wider frustration with enacting theory into practice. Kingsley discussed his desire for a guideline to work with, highlighting the need for individualized mentoring to support him in becoming a well-performing graduate MTEs as mentioned in the literature [3,37]. With respect to competence, the MTEs saw this aspect of their identity as being heavily embedded in their PSTs' perceptions of them as MTEs. In particular, the kinds of experiences the MTEs perceived their PSTs viewed as necessary for a teacher educator to have. When they experienced misalignment with PSTs due to cultural differences, they felt that their credibility was threatened, and that they would not be recognized by faculty or students as competent MTEs.

Navigating the cultural differences around schooling was a consistent struggle for the MTEs. Most challenging were the areas of misalignment in perspectives that were central to how the MTEs identified as a person and educator. In particular, with respect to grading, expending effort, providing feedback, and building warm and supportive teacher-student relationships. These are all core tasks and expectations of the TE role. As we can see from Jai's experience, when there is misalignment between the perspective of the MTE and PSTs, MTEs may struggle to navigate the tension and interpret this conflict as a reflection of their credibility, or lack thereof. In Jai's case, we observed that as a MTE who aimed to support every child with high quality teachers, she identified as a gatekeeper and struggled to lower her grading standards. Thus, among Jai's multiple identities, Jai gatekeeper identity was foregrounded when she assigned a final grade to each PST [24,25]. Jai's gatekeeper identity was salient and competed with her MTE identity to be at the pinnacle of identity hierarchies $[46,47]$. The experiences the MTEs described throughout CoPSS impacted how 
they viewed their credibility as MTEs, especially from the lens of recognition, competence, and performance, all of which are central to the process of developing a professional identity as a teacher educator. In this regard, Carlone and Johnson's framework [12] was useful for conceptualizing the MTE's professional identity development.

Research has shown that immigrant students are often placed in a position where they feel they must leave behind their cultural identity in favor of the dominant culture where they are studying [48]. However, "teachers do not develop their identity in a vacuum, but rather in a context that brings social and cultural forces to bear upon that development" [49] (p. 326). Thus, teacher knowledge of teaching is complex, and culturally dependent; teacher educators must examine their own practice to understand their own evolution, and the "evolving possibilities for their teaching and learning" as they develop their identities [50] (p. 11).

\section{Implications}

\subsection{Creating a Third Space}

As the US becomes increasingly diverse, the nature of the challenges experienced by graduate MTEs are becoming more commonplace in university and K-12 classrooms. In this study, there was a cultural mismatch between the teacher and students. This mismatch did not foster the emotionally nurturing, cognitively demanding learning space that MTEs envisioned creating (and the PSTs perhaps desired). Instead, it engendered doubt and mistrust, leading to the MTEs questioning their own credibility, which disrupted their identity development and potentially derailed learning. The MTEs' classrooms can be seen as a microcosm of what current and future K-12 learning environments will look like. In this context, the PSTs are the teachers. However, given the current and projected demographics of K-12 students [51] it is highly likely that there will be teacher-student culture mismatch in their own classrooms. In this regard, with the goal of optimizing students' learning, teachers must endeavor to bridge the divide, allowing students' cultural background and experiences to stimulate learning. One perspective that provides some guidance is the idea of creating a third space [52] for transformative interaction.

When two culturally different communities work together, the members in the community may create a third space (different from the original space each community was familiar with) for effective collaboration and transformative interactions [52]. "These "in-between" spaces provide the terrain for elaborating strategies of selfhood-singular or communal- that initiate new signs of identity, and innovative sites of collaboration, and contestation, in the act of defining the idea of society itself" [52] (p. 2). Thus, instead of conceptualizing the "in-between" spaces as tensions requiring resolutions, we can frame them as innovative learning sites for both TEs and PSTs. Specifically, by positioning themselves in the third-space, both PSTs and TEs can make an effort to discover and understand the cultural similarities and differences between them. PSTs could treat TEs as a source for learning how to interact with second language learners and understanding diverse learners' cultural beliefs. Meanwhile, TEs could model for PSTs by showing curiosity about PSTs' learning experience and how they can make cultural connections with the PSTs. Having established an identity as a teacher, when MTEs engage in teaching teachers, they need to relearn how to teach some basic concepts as not all the principles developed from prior experiences are translated into the requirements of this new role [53].

The concept of third space recognizes that identities are not constructed in isolation. Communities, especially Communities of Practice, play a critical role in developing new teacher educators as they work together and research together [54]. These spaces can recognize the strong connection between professional identity, self-efficacy, and collegiality as collegial interactions are an important part of developing a professional identity as a teacher educator [55-57].

The idea of preparing teachers who can adjust in this ever evolving and globalized world is to ensure that these PSTs can address the learning needs of the students who are from different countries, as well as for the students who do not look like them. This 
training is not only necessary for teaching in K-12 classrooms, but for engaging with international TEs in their teacher education programs. Having an international instructor can be considered as an asset for learning as the international TE can bring their culture into the classroom from which the PSTs can become more culturally aware and learn how to be inclusive.

\subsection{Designing Courses and Curricula to Support Cultural Awareness and Critical Consciousness}

The international graduate students in the CoPPS program frequently noted throughout the conversations that there was a dual lack of cultural awareness happening in the courses that they instructed. The predominantly white PSTs were exhibiting cultural behaviors such as packing up for class early, which contrasted with the cultural norms embedded in the identities of MTEs. This is problematic for because the MTEs interpreted PSTs' attitudes as indicators of the lesson quality. Thus, the MTEs' efficacy suffered due to a discord in cultural practices and expectations. In fact, intercultural competences rely on more than just intergroup attitudes but also includes an awareness and knowledge of various worldviews and the flexibility to modify behaviors to accommodate multiple cultural perspectives of what teaching and learning resemble in the classroom [58]. A dearth of a multicultural critical consciousness can obstruct PSTs' opportunities to learn what it means to teach and learn in a diverse setting. No doubt, the PSTs future students will represent the increasingly multicultural classroom in the US, and cultural awareness will be paramount to serving each child as well as fostering a healthy classroom community.

It is essential to develop PSTs' cultural competence through awareness, understanding, acceptance and appreciation of cultural diversity [59]. Activities focused on fostering awareness include PSTs and TEs reflecting on and sharing their own identities, and how these influence their developing pedagogies. Modeling these activities in developmentally appropriate lessons could offer the PSTs experiences invaluable to pedagogical development that is supported by growing cultural awareness. Additionally, international TEs could offer their PSTs a chance to develop a deeper sense of awareness and understanding of cultural divergences [60] by highlighting their own cultural influences, practices, history, and language uses. This could be extended further with the creation of curricula that address such cultural divergences, and which PSTs could be learn how to modify their curriculum and incorporate these ideas into the K-12 classrooms. In these types of activities, the relationship between the TE and PST is interactive as well as instructive. Negative interactions can result from cultural misinterpretations teachers have of students (and in this case also the students have for TEs) [61]. Therefore, developing curricula that promotes communication and positive interactions (e.g., storytelling, role-modeling, letter writing) could serve the PST in building cultural awareness as well as promoting efficacy for the TE.

\subsection{Individualized Advising for Graduate MTEs}

Graduate MTEs are learners in doctoral programs which also have a teaching and research faculty. Doctoral students enter their programs from a range of backgrounds and experiences, thus, requiring different kinds of support. Similarly, when supporting learners in any context, optimizing learning for them necessitates that the teacher (i.e., faculty advisor) understand who they are as individuals and professionals, including their goals, beliefs, background and experiences. This knowledge can then be used to create an individualized learning path for MTEs and guide the identification of use of adequate supports. These considerations are particularly important for international graduate MTEs as they are perhaps learning new content and developing new instructional practices to be utilized in a context steeped in cultural norms and expectations that are unfamiliar. Moreover, international graduate TEs may not be aware of these challenges and tensions. Some of them may not necessarily see the role identity and culture plays in their MTE development. Thus, engaging them in activities to raise their attention to who they are to better understand their experience may be important. One approach is to have them write 
their teacher autobiographies or reflect on important events (e.g., [17]) and another is to have graduate TEs engage in the process of self-study [62].

Having negative self-views about oneself (i.e., being isolated, marginalized) hinders in evolving of desirable TE identity [63]. Such views become prominent as entry into an entirely new system takes some time to be familiar with the structures, support networks, organizational knowledge, and expectations related to the role [64]. Rather than thinking of providing emotional support through counselling services to graduate TEs, this should be embedded in the culture of the school, where the faculty and the TEs from the US are aware of the potential turmoil an international person can experience. Having trustworthy and collegial relation with colleagues impacts how one views his/her position and evolves a sense of self as a teacher educator in the learning community [62].

We agree with Williams et al. (2012) that "If teacher education is to advance as a practice and as a profession, then its existing members must recognize and nurture the contributions, struggles, and lived experiences of its newcomers" (p. 252). Along with the host of past experiences, beliefs, knowledge, abilities, attitudes, and identities [64], what shapes MTE's identity is learning what it means to be a member of a new profession (professional socialization; [65]) and learning about the knowledge, values, and behaviors required to survive within an organization [66]. We believe that having support groups, such as CoPSS, which can also be understood as communities of practice, creates avenues for the TEs to take advantage of the learnings of other members through social relationships and co-participation in joint enterprise [21]. We consider generic induction programs to be inadequate to support the complex process of developing one's TE identity, especially for international students. As this study shows, each MTE is distinct and has distinct tensions and challenges related to their role as an MTE; hence, forums such as CoPSS provide 'in-the-moment' support to the TEs more broadly as they engage in the process of becoming a teacher-educator [39].

Author Contributions: Conceptualization: D.C.F., P.K.B., J.L., A.P. and M.P.R.; Formal analysis: D.C.F., P.K.B., J.L., Q.Z., C.C. and K.L.; Methodology: D.C.F., M.P.R. and A.P.; Project administration: M.P.R.; Supervision: D.C.F.; Writing—original draft: D.C.F., P.K.B., J.L., A.P., Q.Z. and C.C.; Writingreview and editing: D.C.F., P.K.B., J.L. and M.P.R. All authors have read and agreed to the published version of the manuscript.

Funding: This research received no external funding.

Institutional Review Board Statement: Ethical review and approval were waived for this study due to all participants being of consenting age and not from vulnerable populations.

Informed Consent Statement: Participant consent was obtained for this study.

Data Availability Statement: Data is not publicly available to preserve participants' anonymity. The corresponding author may be contacted for additional information.

Conflicts of Interest: Authors declare no conflicts of interest.

\section{References}

1. Ball, D.L.; Thames, M.H.; Phelps, G. Content Knowledge for Teaching: What Makes It Special? J. Teach. Educ. 2008, 59, 389-407. [CrossRef]

2. Superfine, A.C.; Li, W. Exploring the Mathematical Knowledge Needed for Teaching Teachers. J. Teach. Educ. 2014, 65, 303-314. [CrossRef]

3. Schutz, P.; Hong, J.; Cross Francis, D. Teachers' Goals, Beliefs, Emotions, and Identity Development: Investigating Complexities in the Profession; Taylor and Francis: New York, NY, USA, 2020.

4. Cross, D. Alignment, cohesion and change: Examining mathematics teachers' belief structure and its influence on instructional practice. J. Math. Teach. Educ. 2009, 12, 325-346. [CrossRef]

5. Nichols, S.L.; Schutz, P.A.; Rodgers, K.; Bilica, K. Early Career Teachers' Emotion and Emerging Teacher Identities. Teach. Teach. 2017, 23, 406-421. [CrossRef]

6. Schutz, P.A.; Pekrun, R. Emotion in Education; Academic Press Inc.: London, UK, 2007.

7. Young, J.R.; Erickson, L.B. Imagining, Becoming, and Being a Teacher: How Professional History Mediates Teacher Educator Identity. Stud. Teach. Educ. 2011, 7, 121-129. [CrossRef] 
8. Day, G. Community and Everyday Life; Routledge: London, UK, 2006.

9. Richter, E.; Lazarides, R.; Richter, D. Four Reasons for Becoming a Teacher Educator: A Large-Scale Study on Teacher Educators' Motives and Well-Being. Teach. Teach. Educ. 2021, 102, 103322. [CrossRef]

10. Schutz, P.A.; Cross, D.I.; Hong, J.Y.; Osbon, J.N. Teacher understandings, thoughts and beliefs about emotions in the classroom. In Emotions in Education; Schutz, P.A., Pekrun, R., Eds.; Elsevier Inc.: San Diego, CA, USA, 2006; pp. 215-233.

11. Schutz, P.A.; Nichols, S.L.; Schwenke, S. Critical Event, Emotional Episodes, and Teacher Attributions in the Development of Teacher Identities; Springer: Singapore, 2018; pp. 49-60.

12. Carlone, H.B.; Johnson, A. Understanding the Science Experiences of Successful Women of Color: Science Identity as an Analytic Lens. J. Res. Sci. Teach. Off. J. Natl. Assoc. Res. Sci. Teach. 2007, 44, 1187-1218. [CrossRef]

13. Zopf, D. Mathematical Knowledge for Teaching Teachers: The Mathematical Work of and Knowledge Entailed by Teacher Education; University of Michigan: Ann Arbor, MI, USA, 2010.

14. Jacobs, V.R.; Spangler, D.A. Research on Core Practices in K-12 Mathematics Teaching; National Council of Teachers of Mathematics: Reston, VA, USA, 2017; pp. 766-792.

15. Jonker, H.; März, V.; Voogt, J. Teacher Educators' Professional Identity under Construction: The Transition from Teaching Face-to-Face to a Blended Curriculum. Teach. Teach. Educ. 2018, 71, 14. [CrossRef]

16. Vanassche, E.; Kelchtermans, G. Teacher Educators' Professionalism in Practice: Positioning Theory and Personal Interpretative Framework. Teach. Teach. Educ. 2014, 44, 117-127. [CrossRef]

17. Tzur, R. Becoming a Mathematics Teacher-Educator: Conceptualizing the Terrain through Self-Reflective Analysis. J. Math. Teach. Educ. 2001, 4, 259-283. [CrossRef]

18. Kelchtermans, G. Who I Am in How I Teach Is the Message: Self-Understanding, Vulnerability and Reflection. Teach. Teach. Theory Pract. 2009, 15, 257-272. [CrossRef]

19. Mead, G.H. Mind, Self and Society; University of Chicago Press: Chicago, IL, USA, 1934; Volume 111.

20. Holland, D.; Lachicotte, W., Jr.; Skinner, D.; Cain, C. Identity and Agency in Cultural Worlds; Harvard University Press: Cambridge, UK, 1998.

21. Lave, J.; Wenger, E. Learning in Doing: Social, Cognitive and Computational Perspectives: Situated Learning: Legitimate Peripheral Participation; Cambridge University Press: Cambridge, UK, 2013.

22. Hargreaves, A. Emotional geographies of teaching. Teach. Coll. Rec. 2001, 103, 1056-1080. [CrossRef]

23. Beijaard, D.; Meijer, P.C.; Verloop, N. Reconsidering Research on Teachers' Professional Identity. Teach. Teach. Educ. 2004, 20, 107-128. [CrossRef]

24. Holmes, J.M.; Bowman, N.A.; Murphy, M.C.; Carter, E. Envisioning College Success: The Role of Student Identity Centrality. Soc. Psychol. Educ. 2019, 22, 1015-1034. [CrossRef]

25. Sellers, R.M.; Chavous, T.M.; Cooke, D.Y. Racial Ideology and Racial Centrality as Predictors of African American College Students' Academic Performance. J. Black Psychol. 1998, 24, 8-27. [CrossRef]

26. Sussman, N.M. The Dynamic Nature of Cultural Identity throughout Cultural Transitions: Why Home Is Not so Sweet. Pers. Soc. Psychol. Rev. 2000, 4, 355-373. [CrossRef]

27. Fitzpatrick, K.R. Cultural Diversity and the Formation of Identity: Our Role as Music Teachers. Music Educ. J. 2012, 98, 53-59. [CrossRef]

28. Beauchamp, C.; Thomas, L. New Teachers' Identity Shiftsat the Boundary of Teacher Education and Initial Practice. Int. J. Educ. Res. 2011, 50, 6-13. [CrossRef]

29. Rahmawati, Y.; Taylor, P.C. "The fish becomes aware of the water in which it swims": Revealing the power of culture in shaping teaching identity. Cult. Stud. Sci. Educ. 2018, 13, 525-537. [CrossRef]

30. Seo, S.; Koro-Ljungberg, M. A Hermeneutical Study of Older Korean Graduate Students' Experiences in American Higher Education: From Confucianism to Western Educational Values. J. Stud. Int. Educ. 2005, 9, 164-187. [CrossRef]

31. Kreber, C. Academics' Teacher Identities, Authenticity and Pedagogy. Stud. High. Educ. 2010, 35, 171-194. [CrossRef]

32. Clemans, A.; Berry, A.; Loughran, J. Lost and Found in Transition: The Professional Journey of Teacher Educators. Prof. Dev. Educ. 2010, 36, 211-228. [CrossRef]

33. Shulman, L.S. Those Who Understand: Knowledge Growth in Teaching. Educ. Res. 1986, 15, 4-14. [CrossRef]

34. Mason, L. Beliefs about Knowledge and Revision of Knowledge: On the Importance of Epistemic Beliefs for Intentional Conceptual Change in Elementary and Middle School Students. In Personal Epistemology in the Classroom; Bendixen, L.D., Feucht, F.C., Eds.; Cambridge University Press: Cambridge, UK, 2010; pp. 258-291.

35. Bergsten, C.; Grevholm, B. Knowledgeable Teacher Educators and Linking Practices; Wood, T., Jaworski, B., Eds.; Sense Publishers: Rotterdam, The Netherland, 2008; pp. 223-246.

36. Chapman, N.; Dempsey, S.E.; Warren-Forward, H.M. Theory of Reflection in Learning for Radiation Therapists. Radiographer 2008, 55, 34-37. [CrossRef]

37. Masingila, J.O.; Olanoff, D.E.; Kwaka, D.K. Who Teaches Mathematics Content Courses for Prospective Elementary Teachers in the United States? Results of a National Survey. J. Math. Teach. Educ. 2012, 15, 347-358. [CrossRef]

38. Newberry, M. Teacher Educator Identity Development of the Non-Traditional Teacher Educator. Stud. Teach. Educ. 2014, 10, 163-178. [CrossRef] 
39. Williams, J.; Ritter, J.; Bullock, S.M. Understanding the complexity of becoming a teacher educator: Experience, belonging, and practice within a professional learning community. Stud. Teach. Educ. 2012, 8, 245-260. [CrossRef]

40. Jones, S.H. Autoethnography: Making the Personal Political; Denzin, N.K., Lincoln, Y.S., Eds.; Sage: Thousand Oaks, CA, USA, 2008; pp. 205-245.

41. Ellis, C.; Kiesinger, C.E.; Tillman-Healy, L.M. Interactive Interviewing: Talking about Emotional Experience; Hertz, R., Ed.; Sage Publications: Thousand Oaks, CA, USA, 1997; pp. 119-149.

42. Corbin, J.; Strauss, A. Strategies for Qualitative Data Analysis. In Basics of Qualitative Research: Techniques and Procedures for Developing Grounded Theory; SAGE: Thousand Oaks, CA, USA, 2008. [CrossRef]

43. Patton, M.Q. Qualitative Evaluation and Research Methods; Sage Publications: Newbury Park, CA, USA, 2002.

44. Skerrett, A. Biography, Identity, and Inquiry: The Making of Teacher, Teacher Educator, and Researcher: Research Article. Stud. Teach. Educ. 2008, 4, 143-156. [CrossRef]

45. Stein, M.K.; Smith, M.S. Five Practices for Orchestrating Productive Mathematics Discussions; Corwin Press: Thousand Oaks, CA, USA, 2011.

46. Stets, J.E.; Burke, P.J. Identity Theory and Social Identity Theory. Soc. Psychol. Q. 2000, 63, 224-237. [CrossRef]

47. Stets, J.E.; Serpe, R.T. Identity theory. In Handbook of Social Psychology, 2nd ed.; DeLamater, J., Ward, A., Eds.; Springer: Dordrecht, The Netherlands, 2013; pp. 31-60.

48. Vellanki, V.; Prince, S.P. Where Are the "People like Me"?: A Collaborative Autoethnography of Transnational Lives and Teacher Education in the US. Teach. Educ. 2018, 53, 313-327. [CrossRef]

49. Van Lankveld, T.; Schoonenboom, J.; Volman, M.; Croiset, G.; Beishuizen, J. Developing a Teacher Identity in the University Context: A Systematic Review of the Literature. High. Educ. Res. Dev. 2017, 36, 325-342. [CrossRef]

50. Kumashiro, K.K. "Posts" Perspectives on Anti-Oppressive Education in Social Studies, English, Mathematics, and Science Classrooms. Educ. Res. 2001, 30, 3-12. [CrossRef]

51. DATA POINT. Race and Ethnicity of Public School. Available online: https:/ /nces.ed.gov/pubs2020/2020103.pdf (accessed on 12 November 2021).

52. Bhabha, H.K. The Location of Culture; Routledge: London, UK, 2019.

53. Bullock, S.M. Learning to Teach Physics Teachers: Developing a Distinct Pedagogy of Teacher Education; Bullock, S.M., Russell, T., Eds.; Springer: Dordrecht, The Netherlands, 2011; pp. 103-120.

54. Wenger, E. Communities of Practice: Learning, Meaning, and Identity; Cambridge University Press: Cambridge, UK, 1998.

55. Dinkelman, T.; Margolis, J.; Sikkenga, K.; Dinkelman, T.; Margolis, J.; Sikkenga, K.; Ritter, J.; Williams, J. From Teacher to Teacher Educator: Experiences, Expectations, and Expatriation. Stud. Teach. Educ. 2006, 2, 5-23. [CrossRef]

56. Dinkelman, T.; Margolis, J.; Sikkenga, K. From Teacher to Teacher Educator: Reframing knowledge in Practice. Stud. Teach. Educ. 2006, 2, 119-136. [CrossRef]

57. Ritter, J. Forging a Pedagogy of Teacher Education: The Challenges of Moving From classroom Teacher to Teacher Educator. Stud. Teach. Educ. 2007, 3, 5-22. [CrossRef]

58. Schwarzenthal, M.; Juang, L.P.; Schachner, M.K.; Vijver, F.J. A Multimodal Measure of Cultural Intelligence for Adolescents Growing up in Culturally Diverse Societies. Int. J. Intercult. Relat. 2019, 72, 109-121. [CrossRef]

59. Ward, M.J.; Ward, C.J. Promoting Cross-Cultural Competence in Preservice Teachers through Second Language Use. Education 2003, 123, 532-536, 638.

60. Keengwe, J. Fostering Cross Cultural Competence in Preservice Teachers through Multicultural Education Experiences. Early Child. Educ. J. 2010, 38, 197-204. [CrossRef]

61. Smith, D.L.; Smith, B.J. Urban Educators' Voices: Understanding Culture in the Classroom. Urban Rev. 2009, 41, 334-351. [CrossRef]

62. Williams, J.; Ritter, J.K. Constructing New Professional Identities through Self-Study: From Teacher to Teacher Educator. Prof. Dev. Educ. 2010, 36, 77-92. [CrossRef]

63. Murray, J.; Male, T. Becoming a Teacher Educator: Evidence from the Field. Teach. Teach. Educ. 2005, 21, 125-142. [CrossRef]

64. Izadinia, M. Teacher Educators' Identity: A Review of Literature. Eur. J. Teach. Educ. 2014, 37, 426-441. [CrossRef]

65. Barnett, M.L. Stakeholder Influence Capacity and the Variability of Financial Returns to Corporate Social Responsibility. Acad. Manag. Rev. 2007, 32, 794-816. [CrossRef]

66. Schein, E.H. Defining organizational culture. Class. Organ. Theory 1985, 3, 490-502. 